Konvansiyonel radyografiden dijitale: intraoral fosfor plak sistemlerinde karşılaşılan artifakt ve hatalar

\section{Conventional radiography to digital: artifacts and errors encountered in intraoral phosphorus plate systems}

\author{
Uzm. Dt. Cansu Görürgöz \\ Ankara Üniversitesi, Diş Hekimliği Fakültesi, \\ Ağız, Diş ve Çene Radyolojisi A.D., Ankara \\ Orcid ID: 0000-0002-3083-1660
}

\section{Arş. Gör. Dt. Nur Hacıosmanoğlu}

Ankara Üniversitesi, Diş Hekimliği Fakültesi, Ağız, Diş ve Çene Radyolojisi A.D., Ankara Orcid ID: 0000-0003-0974-5802

\section{Prof. Dr. Bengi Öztaş}

Ankara Üniversitesi, Diş Hekimliği Fakültesi, Ağız, Diş ve Çene Radyolojisi A.D., Ankara

Orcid ID: 0000-0002-1895-051X

Geliş tarihi: 7 Ekim 2019

Kabul tarihi: 24 Mayıs 2020

doi: $10.5505 /$ yeditepe.2020.76376

\section{Yazışma adresi:}

Dt. Cansu Görürgöz

Ankara Üniversitesi Diş Hekimliği Fakültesi, Ağız, Diş ve Çene Radyolojisi Anabilim Dalı, 06500 Ankara, Türkiye.

Tel: +905454162381

Fax: +903122123954

E-posta: cansu92009@hotmail.com

\section{ÖZET}

Radyografiler, diş hekimliği alanında dentoalveolar ve maksillofasiyal bölgeye ait patoloji ya da hastalıkların tanısında yaygın olarak kullanılmaktadır. Gelişen teknoloji ile birlikte dental görüntüleme pratiğinde dijital radyografi konvansiyonel radyoloji ile karşılaştıııldığında sağ-ladığı avantajlar nedeni ile diş hekimleri arasında giderek tercih edilen bir yöntem olmaya başlamıştır. Charged-Coupled-Device, Complementary Metal Oxide Semiconducter ve fosfor plaklar dijital radyolojide kullanılan sensörlerdir. Fosfor plak sistemleri; konvansiyonel filme olan benzerlikleri, kablosuz olmaları, mevcut film tutucular ile uyumlu olmaları ve diğer dijital sensörlere kıyasla daha ekonomik olmaları nedeniyle daha çok tercih edilen sensörlerdir. Ancak tüm sistemlerde olduğu gibi fosfor plak sistemlerinde de bazı hata ve sorunlar ile karşılaşılmaktadır. Bu çalışmanın amacı konvansiyonel ve fosfor plak sistemlerinde tespit edilen görüntü hataları tanımlamak, oluşum sebeplerine göre hataların nedenlerini ve çözümlerini değerlendirmektir.

Anahtar kelimeler: Radyografi, dijital radyoloji, fosfor plak, artifakt

\section{SUMMARY}

Radiographs are widely used in the diagnosis of pathologies or diseases related to dentoalveo-lar and maxillofacial region in dentistry field. With advancing technology, digital radiography in dental imaging practice has become an increasingly preferred method among dentists due to its advantages compared with conventional radiology. Charged-Coupled-Device, Comple-mentary Metal Oxide Semiconductor and phosphor storage plates are the sensors used in digi-tal radiology. The phosphor storage plates are cordless and similar with conventional films, compatible with existing intraoral film holders, and are more economical than other digital sensors. Therefore, phosphor storage plates are more preferred sensors among all sensors. However, as in all systems, some errors and problems are encountered in phosphor plate systems. The aim of the study was to identify the artifacts detected in conventional and phosphor plaque systems, to evaluate the causes and solutions of the faults according to the occurrence reasons.

Key words: Radiography, digital radiology, phosphor storage plates, artifact

\section{GíRiş}

Radyoloji, x-ışınlarının keşfinden günümüze kadar geçen sürede diş hekimliğinin vazgeçilmez bir parçası olup gelişimini hızla sürdürmektedir., ${ }^{1,2}$

Otto Walkhoff tarafından ilk intraoral dental radyografın elde edilmesinden itibaren yaklaşık 100 yıl kadar gümüş halid esası konvansiyonel filmler diş hekinliğinde tek ve vazgeçilmez görüntü kaydediciler olarak kullanılmıştır., ${ }^{34}$ Günümüze kadar konvansiyonel filmlerin temel prensibi aynı kalmış ancak; yapısal özelliklerinin değiştirilmesi ile ışınlama süresi ve görüntü kalitesi gibi birçok konuda çok önemli gelişmeler kaydedilmiştir. ${ }^{5}$ 
Bilgisayar teknolojisinde yaşanan gelişmeler, farklı birçok dijital radyolojik yöntemin geliştirilmesine olanak sağlamıştır. ${ }^{6,7}$ Önce tıbbi görüntüleme tekniklerini etkileyen bu gelişmeler, 80'li yılların sonlarına doğru dental görüntüleme alanında da yaygınlık kazanmıştır. ${ }^{8}$ Günümüzde dijital sistemler film bazlı konvansiyonel görüntüleme yöntemlerinin yerini almaktadır. ${ }^{1,2}$

Dijital görüntülemenin konvansiyonel radyografiye göre temel avantajları; daha hızı olması, gerçek zamanlı görüntüleme ve iletişimin mümkün olması, karanlık oda prosedürleri ve kimyasallar gerektirmemesi, görüntü iyileştirme araçlarının kullanılabilmesi ve radyasyon dozunu azaltmasıdır. ${ }^{9-11}$ Dijital görüntüleme sistemlerinde görüntü elde edilmesi farklı yöntemlere dayanmaktadır.

1- Solid özellikteki dedektörler yardımıyla yapılan direkt görüntüleme yöntemi [charge-coupled devices (CCD) ya da complementary metal oxide semiconductors (CMOS) sensörler ile düz panel dedektörleri gibi]

2- Geleneksel radyografilerden bir tarayıcı yardımıyla görüntünün elde edildiği indirekt dijital görüntüleme ve fosfor plak (FP) dedektörleri kullanılan yarı direkt görüntüleme yöntemleridir. ${ }^{5}$

CCD ve CMOS sistemlerinde, sensör genellikle bir kablo ile bilgisayara bağlıdır ve görüntü sensörün ışınlanmasından sonra bilgisayar monitöründe hemen görüntülenir. ${ }^{12}$ Ancak bu sistemde uygulayıcının sensörü ışınlamasından sonra hemen hemen anlık bir görüntü oluşmasına rağmen, hastada rahatsızlık yaratan sensör plağının sertliği ve sensörü bilgisayara bağlayan kablonun varlığı ile sensörü oral kaviteye yerleştirmede zorluklar gibi bazı sorunlar mevcuttur. ${ }^{13}$ Buna karşın, FP sistemleri kablosuzdur ve geleneksel filmlerle benzerlik gösterir. Bu sistemde sensör plakları, x-ışını fotonlarını depolanmış enerjiye dönüştüren bir kristal halindeki halojenür emülsiyonu ile kaplanmış bir polyester bazdan oluşur ve bu, daha sonra bir helyum-neon lazer ışınıyla tarandığında mavi floresan ışık olarak salınır. ${ }^{14,15}$ Görüntünün açığa çıkması için önce plakların taranması gerekmektedir. Bu sistem ağız boşluğu içinde kolay ve rahat bir sensör yerleştirme avantajına sahiptir ve bu nedenle hasta için uygundur. ${ }^{16}$ Ancak görüntü elde edilme sürecinin indirekt doğasından dolayı işlem süresi uzamıştır. Ayrıca ek ekipman kullanımı gerektirir. ${ }^{17}$ Tarama süreleri, kullanılan tarayıcı türüne ve görüntünün uzaysal ve kontrast çözünürlüklerine bağlı olarak birkaç saniye ile birkaç dakika arasında değişir. ${ }^{10}$ FP plakları, dental filmlere benzer bir şekilde çeşitli boyutlarda üretilir ve kullanım sırasında bükülme ve çizilmelere karşı hassastır.1,10,17 Bununla birlikte, bu plakların yeniden kullanılabilir olması amaçlanmıştır ve bu nedenle, konvansiyonel filmlerden daha fazla dikkatle kullanılmalıdır. ${ }^{1}$ Literatürde FP sistemlerinin birbirleri ve diğer reseptörler ile karşılaştıran birçok çalışmada farklı sonuçlar olmakla birlikte FP sistemlerinin görüntü kalitelerinin diğer reseptörlere benzer veya daha iyi olduğu bildirilmiştir. ${ }^{18}$ Son yıllarda piyasaya sürülen FP sistemlerinde kullanılan plakların boyutlarının ve fleksibilitesinin periapikal filmlere çok yakın olması, reseptörün ağız içindeki manüplasyonunu daha da kolaylaştırmıştır. ${ }^{2}$ Her gelişen teknolojide olduğu dijital radyografi de, uygulayıcıların üstesinden gelmesi gereken yeni ve farklı zorluklar üretmektedir. ${ }^{13}$ Literatürde FP sistemlerinin çeşitli özelliklerini araştırmış birçok çalışma yer almaktadır. ${ }^{10,12,19-23}$ Ancak bunların çoğu; gecikmiş tarama ve görünür ışığın FP üzerindeki etkileri24-27 ya da hasarlı FP'lerin görüntü kalitesine etkileri ile ilgilidir. ${ }^{17,28}$ Film bazlı radyolojide karşılaşılan intraoral radyografik hatalar ve artifaktlar iyi bilinmektedir. Ancak, bilgilerimize göre, FP teknolojisine özgü görüntü hatalarını ve artifaktları diş hekimliği uygulamaları için belirleyen ve sınıflandıran çok az sayıda çalışma vardır. ${ }^{13,29-31}$

Bu güncel derlemenin amacl; FP ve konvansiyonel sistemlerde karşılaşılan artifaktların ortak noktalarını ve farklılıklarını, nedenlerini ve çözümlerini ortaya çıkararak uygulayıcıların bu sistemleri daha rahat ve bilinçli olarak kullanmalarına yardımcı olmaktır.

\section{A-) İntraoral Görüntüleme Sistemlerinde Karşılaşılan Ortak Artifaktlar (Konvansiyonel ve Fosfor Plak) \\ 1- Operatör ve Hasta ile İlişkili Hatalar}

Operatör ve hasta ile ilişkili hatalar, görüntüleme yönteminden bağımsız, tüm görüntüleme teknikleriyle elde edilen radyograflarda aynı özelliklerde görülebilen hatalardan oluşmaktadır.

\section{a) Teknik Uygulamaya Bağlı Artifaktlar}

Cone-cut; intraoral görüntülemede röntgen tüpünün hasta yüzünde doğru konumlandırılmamasına bağlı olarak, tüpün imaj reseptörünün tamamını kapsamaması sonucu imaj reseptörü üzerinde, değişik boyutlarda, ışınlamamış alan anlamına gelmektedir. Herhangi bir sebeple x-ışını, reseptör ve objenin yanlış açılandırılması sonucu oluşur. ${ }^{32}$ Eğer film/plak ışınlama alanının dışında kalırsa o bölgeler ışın almaz ve kolimatörün şekline göre yuvarlak veya köşeli radyoopak görüntü izlenir (Resim 1a).

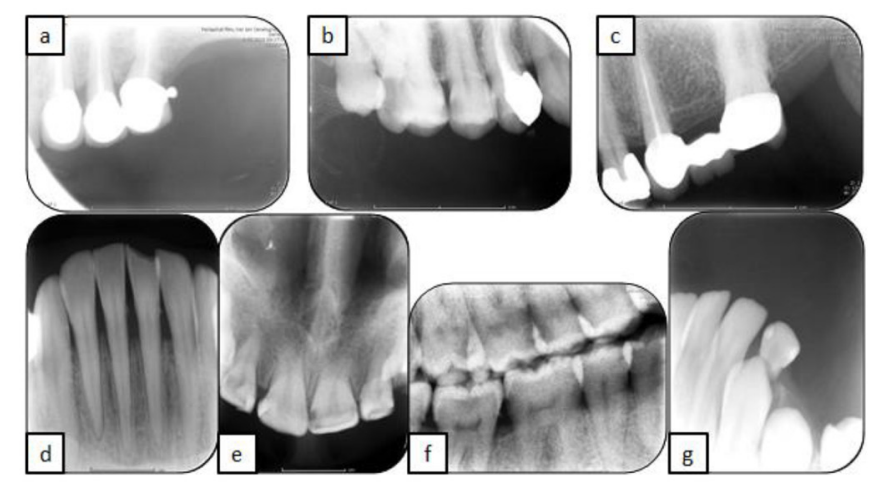

Resim 1. Teknik uygulamaya bağlı artifaktlar. a. Cone-cut, b. Plağın yanlış konumlandırılması sonucu apikal bölgenin kesilmesi, c. Oklüzyona paralel olmayan plak konumlaması, d. Uzamış görüntü, e. Kısalmış görüntü, f. Horizontal açılama hatası, g. Distorsiyon.

İmaj reseptörü ağız içine yerleştirilirken her zaman dişlerin oklüzal seviyelerinden 3-4 mm aşağıda (üst çene için) veya yukarıda (alt çene için) ve incelenen alan imaj resep- 
törünün merkezinde olmalıdır. ${ }^{33}$ Dikkat edilmediğinde oklüzal yüzler veya kök apeksleri görüntüye girmez (Resim 1b). Ayrıca oklüzyona paralel olmayan imaj reseptörü konumlaması gibi hatalar da izlenebilmektedir (Resim 1c). Intraoral görüntüleme tekniklerinden açıortay tekniği, sıklıkla kullanılmakta olup basit bir geometrik teoreme dayanmaktadır. Bu teknik; merkezi ışının, dişin ve imaj reseptörünün uzun aksı arasındaki açının açıortayına dik gelecek şekilde uygulanması esasına dayanır. Röntgen cihazının vertikal yönde uygun olamayan açılanması sonucu eğer merkezi ışın dişe dik gelirse görüntünün boyunda uzama, merkezi ışın imaj reseptörüne dik gelirse görüntünün boyunda kısalma olarak karşımıza çıkar (Resim 1d ve $1 e$ ). Horizontal yönde yapılan açılama hatasına bağlı olarak merkezi ışının interproksimalden geçmeyip horizontal yönde yanlış açılanması ise süperpozisyon (üst üste binme) oluşumuna neden olacaktır (Resim 1f). ${ }^{34}$

Distorsiyon, imaj reseptörünün damak veya ağız tabanı üzerinde bükülmesi durumunda ortaya çıkar. Bu, bükülme görüntüde rüzgara kapılmış bir oluşuma neden olur (Resim 1g). Bunu önlemek için imaj reseptörü nazikçe desteklenmeli ve ağız içerisinde bükülmemelidir. ${ }^{33}$ Mümkün olduğu kadar bükülmeden düz bir şekilde tutulmalıdır.

Işınlama esnasında incelenmek istenilen bölgede yer alan hareketli protezler, gözlük, küpe, pearcing gibi apereyler radyoopak görüntü verir ve bölgenin görüntüsünü engeller. ${ }^{33}$

Chiu ve ark., ${ }^{13}$ intraoral ve ekstraoral FP görüntülerinde artifaktlarl; operatör hataları, tarayıcı hataları ve sensör kusurları başlıkları altında incelemiştir. Çalışmada görüntü artifaktlarının en çok operatör hatalarından kaynaklandığı tespit edilmiş (\%86,2, $n=554 / 643$ ), bu grup içerisinde en sık gözlenen artifaktlar, cone-cut (\%27,62, $n=153 / 554)$ ve distorsiyon $(\% 25,45, n=141 / 554)$ olarak belirtilmiştir. Yazarlar bu durumun, çalıştıkları departmanın bir eğitim kurumu olması ve bazı görüntülerin öğrenciler tarafından alınmasına bağıı olabileceğini belirtmiştir. Deniz ve Kaya, ${ }^{31}$ FP artifaktlarını; operatör hataları, ortam ışığına bağlı artifaktlar, plak, tarayıcı ve yazılım artifaktları olarak sınıflandırdıkları çalışmada benzer şekilde en sık karşılaşılan hataların operatör kaynaklı $(\% 34,7)$ olduğunu bildirmiştir. Bu kategoride en yaygın nedenin projeksiyon geometrisine bağlı hatalar $(\% 31,9)$ olduğu bulunmuştur.

\section{b) Hareket Hatası}

Diş hekimliğinde ışınlama esnasında röntgen cihazının, hasta başının veya imaj reseptörünün hareket etmesi sonucunda radyografik görüntüde detay kaybı (netlik kaybı) şeklinde artifakt görülür. ${ }^{35}$

Hasta hareketi genellikle görüntüdeki nesnelerde "birbirini takip eden" görüntü ile sonuçlanır. İmaj reseptörünün hareketi; hastanın, genellikle rahatsızık duyması nedeniyle ısırma bloğu üzerinde ısırma basıncını bıraktığı için olu- şur. Bundan dolayı dişler ve ısırma bloğu arasındaki mesafe artar ve dişlerin apikal görünümleri azalır (Resim 2a).
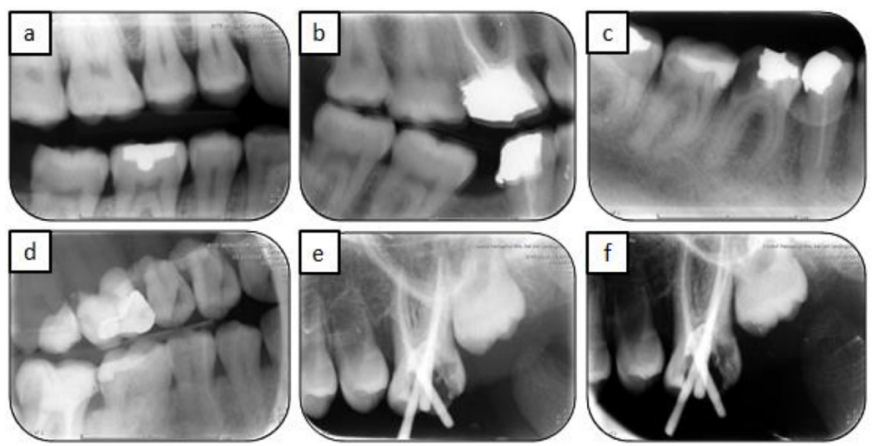

Resim 2. Operatör ve hasta ile ilişkili hatalar. a,b. Hareket hatası, c. Ters çekilmiş plak görüntüsü, d. Çift ışınlama, e. İdeal ışınlama parametreleri, f. Çok koyu görüntü.

Röntgen cihazının hareketi, fokal spotun boyutunu efektif şekilde artıırı. Bu durum, görüntüdeki objenin görünür penumbra ve yarıgölge ile birlikte total magnifikasyonunu artııı (Resim 2b). Röntgen cihazının hareketi; bakımlarının düzenli olarak yapılmadığı ve hasta konforsuzluğu nedeniyle operatörün acele ettiği zamanlarda ortaya çıkar. ${ }^{35}$

c) İmaj Reseptörlerinin Ters Çekilmesi

Ağız içine ışınlama yüzü ters yerleştirilerek ışınlanan imaj reseptörlerinde görüntü ters taraf (sağ-sol/sol-sağ) olarak yorumlanabileceğinden, tanı ve tedavide yanlışlara neden olabilmektedir. Konvansiyonel filmler ters yerleştirildiğinde içerisindeki kurşun levha radyasyonun bir kısmını filtreler ve radyografta filmin hızına göre değişen kabartmalı desen örnekleri izlenir. FP sisteminde ise plakların ters yüzeyine farkın anlaşılabilmesi için radyoopak görüntü veren metal şekiller yerleştirilmiştir. Böylelikle plak ters yerleştirildiğinde elde edilen görüntüde bu şekil izlenmekte ve hekimi uyarmaktadır (Resim 2c). Bazı sistemlerde ise Işınlanacak yüzeyde harfler yer almakta ve ters yerleştirilen plakta bu harfler ters olarak görünmektedir. Ters çekilmiş görüntüler bilgisayar ortamında ayna görüntüsü fonksiyonuyla düzeltilebilir. ${ }^{13}$

\section{d) Çift ışınlama (Double expose)}

Aynı film ya da plağın yanlışlıkla banyo işlemi/tarama işlemini gerçekleştirmeden iki farklı ışınlamada kullanması sonucu oluşmaktadır (Resim 2d). ${ }^{29}$

\section{2- Işınlama ile iliş̧kili Artifaktlar}

Görüntü oluşturmak için 3 ana faktör olan kVp, mA ve x-ışını kaynağı ile imaj reseptörü arasındaki mesafenin uyumu oldukça önemlidir. Gerekli ışınlama parametreleri, kullanılan görüntüleme sisteminin türüne de bağlıdır. ${ }^{36}$ Dijital radyografi sistemleri, konvansiyonel yöntemlerden daha toleranslıdır. Bu sistemin geniş ışınlama parametresi aralığı, genellikle tanısal açıdan kabul edilebilir bir görüntü sağlarlar. Bu, ekspozür toleransı olarak bilinir. ${ }^{37} \mathrm{FP}^{\prime}$ lerin geniş tolerans aralığı ve yazıımlar yardımıyla otomatik parlaklık ve kontrast ayarı optimizasyonu yapılabilmesi, gerekli radyasyon dozunu azaltır. Bu sistemler, yanlışışınlama parametreleri seçimine daha toleranslı olmasına rağmen, fazla gürültüyü, kontrast kaybını ve düzeltme aralığı- 
nın dışında bir sinyali telafi edemez. ${ }^{38}$

\section{a) Çok Koyu Görüntü}

Eğer ışınlama parametreleri radyografisi istenen bölgenin yapısal özellikleri ve sensör karakteristiğine uygun olmayıp olması gereken değerden fazla ise, fazla ışınlama sonucu çok koyu radyografik görüntü oluşacak ve detay kaybına neden olacaktır (Resim $2 \mathrm{e}$ ve $2 \mathrm{f}$ ).

\section{b) Çok Açık Görüntü}

Eğer ışınlama parametreleri radyografisi istenen bölgenin yapısal özellikleri ve sensör karakteristiğine göre olması gereken değerlerden daha az ise az ışınlamaya bağlı çok açık radyografiler elde edilir. Bu görüntüler dikkatle okunmalıdır; çünkü zor fark edilen bulgular, azalmış sinyal-gürültü oranı ile maskelenebilir. ${ }^{38}$

\section{3- Ortam Işığı ile İlişkili Artifaktlar}

Konvansiyonel filmler hem görülebilir ışığa hem de x-ışınına duyarlıdır. İntraoral filmler ambalajından çıkarılırken, karanlık odaya ışık sızması veya odanın ışığının açılması sonucu filmin ışık alan kısımları banyo işleminden sonra siyah renkte görülür. Film uzun süre kırmızı ışık altında tutulursa, kırmızı ışığa yaklaştırılırsa, kırmızı ışığın şiddeti yüksek olursa radyografide ışık foguna neden olur ve puslu bir görüntü oluşur. ${ }^{39}$

Fosfor plaklar, x-ışını tarafından uyarılınca foton enerjisini bünyesinde absorbe eder ve saklarlar. Bu evre latent imaj olarak adlandırılır. Ancak latent imajı oluşturan elektronlar karasızdır.,40 Bu durum, elektronların zamanla kendiliğinden salınabileceği anlamına gelmektedir. Yüksek sıcaklık, artan ortam ışığı yoğunluğu ve süresi, özellikle düşük dozda ışınlama; latent imaj üzerinde salınımı hızlandırır ve zararlı etkileri vardır. Klinik olarak, salınımın en önemli nedeni, gecikmiş taranma ve kılıfsız plağın ortam ışığına maruz kalmasıdır. FP'lerin bu davranışı önemli bir sinyal kaybına neden olabilir. Bu durum sinyal-gürültü oranında (bir görüntüdeki istenilen bilginin; istenmeyen, bilgiyi kısıtlayan kısmına oranı) azalma ve ortalama gri değerinde (Dijital görüntüleri oluşturan her bir pikselin, algılanan radyasyona göre belirlediği değer) artışı beraberinde getirecektir. ${ }^{24,25}$ Değişen sinyal kaybı, gürültülü bir görüntü oluşturur. Bununla birlikte, daha koyu görüntü alanları ortam ışığından daha fazla etkilenir. ${ }^{25}$

\section{B-) Fosfor Plak Sistemlerine Ait Artifaktlar 1-Ortam Işığı ile İlişkili Artifaktlar}

\section{a) Gürültü}

Gürültü, gerçek sinyallerle etkileşime girerek görüntüyü bozan rastgele sinyallerdir.36 Sonuçta aynı yapısal alanlar için rasgele densite varyasyonları gösteren grenli bir görüntü izlenir (Resim 3a).

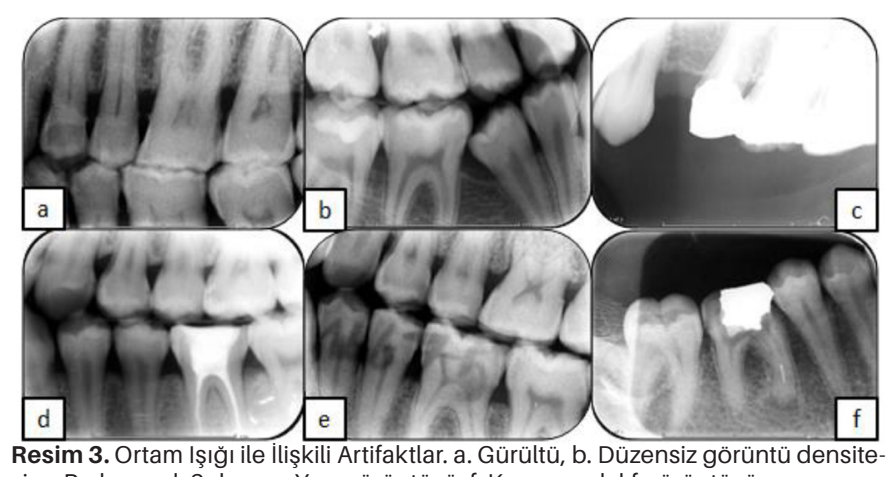
si, c. Parlama, d. Solma, e. Yazı görüntüsü, f. Koruyucu kılıf görüntüsü.

Dijital bir görüntüdeki gürültünün nedeni; gecikmiş tarama, çok yoğun ortam ışığı ve ışınlama sonucu elektronların kendiliğinden salınmasının latent imajda düzeltilemez değişiklikler yaratmasıdır. ${ }^{29}$

\section{b) Düzensiz Görüntü Densitesi}

Bu hata çoğunlukla aynı hastaya ait birden fazla plağın kılıflarından çıkarıldıktan sonra tarama işlemine kadar düzensiz olarak üst üste bekletilmesi ve tarama işleminin gecikmesi nedeniyle oluşur. Eğer plağın tüm yüzeyi ortam ışığından etkilenmez ise yani ortam ışığı plak yüzeyini kısmen etkilemişse ışığa maruz kalan alanlarda görüntünün densitesinde azalma meydana gelirken, korunan alanda normal densitede olur. Görüntü üzerinde aynı yapılar için farklı densite gösteren iki veya daha fazla radyografik alan izlenir (Resim 3b). ${ }^{29}$

\section{c) Parlama}

Bu artifakt saf beyaz alanlar olarak genellikle amalgam ve sabit protetik restorasyonlar gibi atenüasyon (x-ışını tutma derecesi) değerleri yüksek radyoopak yapıların merkezinde ve görüntünün periferal sınırlarında oluşur. Bu alanlarda aşırı spontan salınım nedeniyle, kazanılan sinyalin total kaybıdır. Parlama artifaktı, önemli ölçüde gürültülü bir görüntü ile birlikte ortaya çıkar (Resim 3c). ${ }^{29}$

\section{d) Solma}

Gecikmiş tarama nedeniyle kılıfsız plağın ortam ışığına maruz kalması, latent imajı oluşturan elektronların tolere edilebilir kendiliğinden salınması ve yetersiz ışınlama nedeniyle oluşur. Görüntü kalitesinin azaldığı normalden daha açık radyografik görüntü ortaya çıkar (Resim 3d). ${ }^{29}$ Aşırı gecikmiş tarama ve ortam ışığı maruziyeti sonucu düşük enerjili fotonlar tarafından üretilen zayıf sinyaller önce kaybolur. ${ }^{29}$ Görüntünün elde edilmesi ve işlenmesi arasında bir gecikme, görüntünün solmasına yol açacaktır. Bu solmanın olası nedeni, merkezi ışının yüksek enerjili fotonlardan oluşması, düşük enerjili fotonların ise periferde olmasıdır. Bu nedenle solma periferden başlar. Bu özellik, yetersiz ışınlama nedeniyle ortaya çıkan solmadan ayırmaktadır. ${ }^{38}$ Ayrıca yetersiz ışınlamaya bağlı solma artifaktına, gecikmiş tarama olmasa bile gürültü de eşlik etmektedir.

\section{e) Yazı Görüntüsü}

Konvasiyonel radyografide, ışınlama öncesi filmin üzerine bastırılarak yazı yazılması radyoopak, bu işlemin ışınla- 
ma sonrası yapılması radyolüsent izler kalmasına neden olur. ${ }^{39} \mathrm{FP}$ sisteminde ise plaklar ve not kağıdı üst üste konulduklarında ve tarama işlemi geciktiğinde, not kağıtları üzerindeki yazılar elde edilen radyografik görüntüde izlenebilmektedir. Bu hata, yazı görüntüsü olarak adlandırıımıştır (Resim 3e).. ${ }^{29}$ Ayrıca ışınlama sonrası koruyucu kartonu olmadan kılıfı ile bekletilen plaklardan elde edilen görüntüde kılıfın yapısı izlenebilmektedir (Resim 3f). Plaklar, tarama işleminden hemen öncesine kadar karton kııflarından çıkartılmamalı ve kılıfsı plaklar herhangi bir nesne üzerine veya altına koyulmamalıdır.

Çalışkan ve Sumer'in çalışmasında ortam ışığına bağlı artifakt grubunda en sık solma (\%44,1, $n=926 / 2100)$ ve slrasıyla düzensiz görüntü densitesi (\%18,2, $n=382 / 2100)$, gürültü (\%7,6, $n=160 / 2100)$, parlama (\%1,5, $n=32 / 2100)$ ve yazı görüntüsü $(\% 0,8, n=17 / 2100)$ tespit edilmiştir. Araştırmacılar solma artifaktının yüksek oranda görülmesine sebep olarak, ışınlamadan sonra kontaminasyonu önlemek için plaklarının kılıflarından çıkarılmasını göstermişlerdir. ${ }^{29}$ Deniz ve Kaya, ${ }^{31}$ yaptıkları çalışmada tüm artifaktlar arasında operatöre bağlı hatalardan sonra en çok görülen artifaktın solma olduğunu belirtmişlerdir. Bu çalışmada ortam ışığı ile ilişkili artifaktlar görülme sıklıklarına göre sırasıyla; solma, gürültü, düzensiz görüntü densitesi, parlama, yazı görüntüsü ve ışınlamadan önce FP'nin ışığa maruz kalmasıdır. ${ }^{31}$

FP'lerin taranması için önerilen ortam koşulları üretici firmalara göre değişmektedir. Gendex (Des Plaines, IL) firması FP'lerin hafif ortam aydınlatması altında kullanımasını önerir. ${ }^{41}$ Air Techniques (Hicksville, NY), ekspoze FP'lerin taraması sırasında 400 lux'e kadar normal oda aydınlatmasının kabul edilebilir olduğunu savunmaktadır. ${ }^{42}$ Dürr Dental (Bietigheim-Bissingen, Germany) firması ise normal aydınlatma koşullarını önermektedir (1000 lux'e kadar). ${ }^{43}$ Bazı araştırmacılar tarama için yarı karanlık oda kullanımını tavsiye etmektedir. ${ }^{10,24,44}$

Görünür ışık spektrumunda; latent imaj, FP'lerin taranmasında kullanılan katı-hal lazerlerin $(620-633 \mathrm{~nm})$ dalga boyuna daha yakın olan kırmızı ısığa $(600 \mathrm{~nm})$ en duyarlıdır. ${ }^{45}$ Bu nedenle, kırmızı ışıklı geleneksel karanlık oda, sıradan oda ışığı ile karşılaştırıldığında, sinyal bozulmalarını teorik olarak hızlandırabilir.

Molteni'ye göre, solma doğrusal olmayan, yani ilk hızlı sinyal kaybından sonra, bir süre boyunca yavaşlama eğilimindedir. Bu nedenle, ışığa maruz kalmanın ilk birkaç anı görüntü kalitesi için çok önemlidir. ${ }^{46}$

Ramamurthy ve ark. ${ }^{24}$ ortam aydınlatma yoğunluğunu ve süresinin, 2 farklı FP sisteminde sinyal-gürültü oranına etkisi araştırmış ve bu oranı, 2 dakikaya kadar çeşitli zaman aralıklarında hesaplamışlardır. sinyal-gürültü oranı, ışığa maruz kalma süresi artıkça doğrusal bir şekilde azalmış, yüksek yoğunluktaki ortam aydınlatması ve daha uzun gecikme zamanında sert şekilde düşmüştür.
Eskandarloo ve ark. ${ }^{47}$ FP'leri x-ışını ekspozüründen sonra taramadan önce 4 farklı ortamda (beyaz ışık, sarı ışık, doğal ışık ortamı ve karanlık oda) değişen zaman aralıklarında bekletmiş ve bu faktörlerin görüntü kalitesi üzerindeki etkisini araştırmışlardır. Sarı ışığın, FP görüntülerinin kalitesi üzerinde farklı bir etki gösterdiği ve görüntülerin kontrastını azalttığı tespit edilmiştir. Bu araştırmacılar, FP'lerinin taranması için tamamen karanlık bir odaya gerek olmadığını, ancak sinyal bozulmasını önlemek için, azaltılmış ortam aydınlatması kullanımını önermiştir.

Martins ve ark. ${ }^{26}$ FP'lerin, ışınlamadan sonraki 5 dakika içinde bilgileri kaybetmeye başladığını ve bilgilerin neredeyse yarısının 1 saat içinde kaybolduğunu bildirmiştir. Akdeniz ve ark. ${ }^{25}$ latent imajın, tarama 10 dakikadan daha fazla geciktiğinde kaybolmaya başladığını tespit etmiştir. Ayrıca bazı plaklarda 30 dakika sonra latent imajın \%23'ü, 1 saat sonra \%30'unun kaybolduğu belirtilmiştir. Latent imaj bozulması plak yüzeyinde aynı olduğu için, erken şarj kaybı genellikle klinik olarak anlamlı bir görüntü bozulmasına neden olmaz. Bununla birlikte, düşük dozda ışınlanmış görüntülerde, belirgin bir görüntü bozulması olabilir. ${ }^{34}$ Plaklar, $x$-ışını ekspozundan sonra mümkün olan en kısa sürede taranmalıdır. ${ }^{29}$ Plakların kılıftan çıkartılıp taranması aşamasında hızlı davranılarak plakların ortam ışığına maruziyetinin en aza indirilmesi sağlanmalıdır. ${ }^{24,46}$ Özellikle ortam ışığın fazla olduğu yerlerde taşıyıcılı sistemler yerine, plağın tarayıcıya doğrudan yerleştirildiği sistemler tercih edilmelidir. ${ }^{48}$

\section{2- Fosfor Plak ile İlişkili Artifaktlar}

Fosfor plak ile ilişkili hatalar oluşturucu faktörlere göre 2 gruba ayrılmıştır.

\section{a) Fotostimule Luminesans Tabaka Hasarı}

Mekanik stresler, fotostimule luminesans tabakanın hasarında temel faktörlerdir. Aşırı bükme, basınç, sürtünme, ısırma ve yıpranma bu hasarın olası nedenleri olarak bildirilmiştir., ${ }^{1,26}$

Çatlak: Genellikle plakanın ağız içerisine konumlandıııması sırasında aşırı bükülmesi ve yanlış manipülasyonu sonucu fotostimule luminesans tabakada ve destekleyici polyester tabanda geri dönüşü olmayan hasarlardır. Genellike bitewing radyografilerinde oklüzyon seviyesinde lineer, düzensiz radyoopak çizgi olarak izlenir (Resim 4a). 


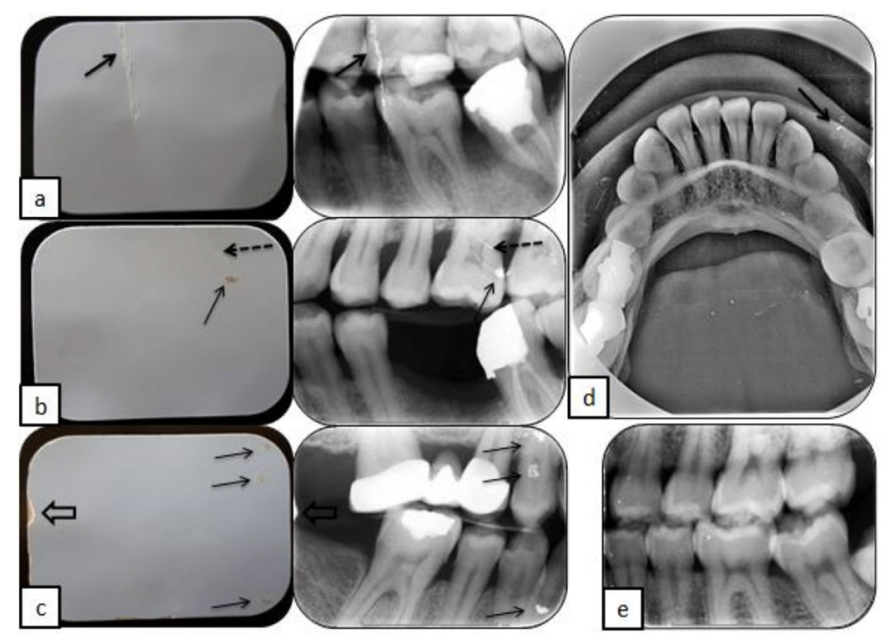

Resim 4. Fosfor plak ile ilişkili artifaktlar. a. Çatlak (siyah ok), b. Çizik (kesikli ok) ve kir (ince siyah ok), c. Plak kenarında soyulma (içi boş siyah ok) ve adeziv kontaminasyonu (ince siyah oklar), d. Isırma izleri (siyah ok), e. Plak üzerinde kalmış olan toz parçacıkları.

Çizikler, destekleyici polyester tabanda bükülme olmadan fotostimule luminesans tabakanın hasarı sonucu oluşur. Görüntünün herhangi bir yerinde küçük, lineer pürüzsüz opasiteler olarak gözlenir (Resim 4b). Görüntü edinilmesi sırasında, özellikle plağın taranma ve silinme işlemleri çizikler için ana faktörler olarak kabul edilmiş̧̦ir. 28,49

Plak kenarlarının soyulmasi: Plak, taşıyıcı kasete yerleştirildiğinde sürtünme sonucu FP sınırlarında koruyucu ve fotostimule luminesans tabakaların soyulması nedeniyle oluşur. Bu hasarın oluştuğu plaklar kullanılarak elde edilen görüntülerin kenarlarında bozulma ve düzensizlikler izlenir (Resim 4c). Chiu ve ark.ları, yetersiz klıflama sonucu tükürük kontaminasyonunun, plak sınırları üzerinde soyulma etkisi olabileceğini öne sürmüş̦ür. ${ }^{13}$

Isırma izleri, özellikle oklüzal radyografilerde, hastalar güçlü bir şekilde ısırdıkları zaman görüntüde küçük çok sayıda düzensiz radyoopak noktalar ve plak yüzeyinde küçük çukurlar şeklinde gözlenir (Resim 4d).

Hilal şeklinde bükülme, hastalar ısırma bloğunu yanlış bir şekilde ısırdığında, kilıf ve plaka üzerindeki gerilme oluşur. Görüntü üzerinde hilal şeklinde bir radyoopasite ve plakanın karşıık gelen bölgesinde hilal şeklinde bir bükülme görülür.

Çalışan ve Sumer, ${ }^{29}$ yaptıkları çalş̧mada fotostimule luminesans tabaka hasarları arasında en çok plak kenarlarının soyulmasını (\%53.4, $\mathrm{n}=1121 / 2100)$ ve çizik (\%41.5, n = 871/2100) varlığını tespit etmiştir. Deniz ve Kaya'nın çaış̧masında plak ile ilişkili artifaktlar tüm artifaktlar arasında üçüncü sıradadır ve bu grup içinde en sık kısa çizikler (n $=267 / 623)$, kısmi soyulma $(n=132 / 623)$ ve hilal şeklinde bükülme $(n=105 / 623)$ görülmüştür. ${ }^{31}$ Bu iki çalışmada plakların fiziksel hasar insidansı benzerdir; ancak bu sonuçların, Chiu ve ark. ${ }^{13}$ ile Gulsahi ve ark. ${ }^{30}$ tarafından bildirilenden çok daha yüksek olduğu görülmüştür. Deniz ve Kaya ${ }^{31}$ bu durumu, FP'lerin yüksek maliyeti nedeniyle gerektiğinde yeni plakların satın alınamaması olarak açıklamışıır.

Bedard ve ark., ${ }^{50} \mathrm{FP} l e r i n 50$ kullanımdan sonra çok za- rar gördüğünü bildirmiştir. Benzer şekilde Kalathingal ve ark. ${ }^{28}$ klinik olarak rastgele seçilen FP'lerin \%25'inin yüzey çizikleri nedeniyle kötü ve okunamaz olarak değerlendirildiğini ve plakların ortalama olarak yaklaşık 50-70 kullanıma maruz kaldığını belirtmişlerdir. Ergun ve ark. ${ }^{48}$ çalışmalarında kullandıkları FP sistemi için plakların bozulmadan 200 kullanıma kadar kullanılabileceğini belirtmiş, Buchanan ve ark. ${ }^{51}$ ise $\mathrm{FP}^{\prime}$ lerin klinikte 48 kez kullanılmasının ardından uzaysal çözünürlükte bir bozulma tespit etmişlerdir. Çalışmalardaki bu sonuçların materyal ve yöntem farklııklarından kaynaklandığı düşülmektedir.

Plakların yerleştirildiği plastik paketlerin asıl amacı enfeksiyon kontrolü sağlamak olmasına rağmen görünür ışığa karşı da bir bariyer oluşturur; ancak bükülme, film tutucu ya da diş izlerinden kaynaklanan mekanik aşınmalara karşı yeterli koruma sağlamaz. ${ }^{13}$ Üreticiler, plaklardaki mekanik hasarı en aza indirmek için koruyucu kılıf kullanılmasını tavsiye etmektedir. ${ }^{52,53}$ FP hasarı, plak kılıfının etrafına çift taraflı bant parçaları yerleştiren Roberts ve Mol'ün yöntemi kullanılarak engellenebilir. ${ }^{17} \mathrm{Hem}$ karton kılıfların hem de tek kullanımlık plastik paketlerin kullanımının FP'nin zarar görmesini önlediği bildirilmiştir; ancak bu, tek kullanımlık paketlerdeki FP'lerin hareketine de neden olur. ${ }^{54}$ Üretici firmalar tek kullanımlık paketlerin yapışkan tarafından açmayı ve FP'yi koruyucu kılıfıyla tarayıcının giriş ünitesine yerleştirmesini önermektedir. FP daha sonra, otomatik olarak içeri çekilene kadar koruyucu kılıfından ünitenin içine doğru kaydırılmalıdır. ${ }^{53} \mathrm{Bu}$ işlemin amacı, kullanıma ve ortam ışığına bağı hata ve artifaktları önlemektir.

Görüntü elde edilmesinin her aşamasında plak operatör tarafından dikkatli bir şekilde nazikçe uygulanmalı; bitewing ve oklüzal radyografilerde ısırma kuvvetinin kontrollü olması sağlanmalıdır. Hasarlı plaklar düzenli kontrollerle belirlenip kullanımdan çıkarılmalıdır.

\section{b) Plaka yüzeyinde kirlenme}

Plaktaki kir, fosforesans ve sinyal edinimi için gerekli olan uyarıcı lazer ışığını bloke eder. Bu alandaki görüntü, sinyal edinimi olmadığı için radyoopak olarak görülmekte ve bir bloke edici ajan şeklini almaktadır. Siyah taraftaki kir bir artifakta neden olmaz, sadece plağın aktif tarafındaki kir görüntü artifaktı yaratır. Toz parçacıkları, eldiven pudrası ve vücut yağı plaktaki kir için rapor edilen maddelerdir.' Plak üzerinde kalmış olan toz parçacıkları, tarama işlemi sonunda görüntünün herhangi bir yerinde radyoopak noktalar şeklinde karşımıza çıkar (Resim 4e). ${ }^{29}$ Bu atrifakt, plak yüzeyindeki kirlenmeler arasında en sık karşılaşılan gruptur. ${ }^{29,31}$

Eldiven pudrası kontaminasyonu ise ter ve vücut yağının etkisiyle birlikte plak yüzeyinde birikmesidir. Görüntüde granüler radyoopak kümeler olarak izlenir. ${ }^{29}$

Parmak izi, Operatörün parmaklarındaki vücut yağı ve kir gibi lazer ışınının plağa ulaşmasını engelleyebilecek kon- 
taminasyonlar radyografide radyoopak parmak izi görüntüsü olarak görüntülenir. ${ }^{23}$

Adeziv kontaminasyon; plağı kılıflarken kılıfın yapışkan bandından adeziv kontaminasyonu ve bu adeziv bölge üzerine toz birikmesi, genellikle plağın kısa kenarlarına yakın olan düzensiz bir radyoopak alan oluşumuna yol açabilir (Resim 4c). ${ }^{23}$

Operatör tarafından dikkatli manipülasyon ve plakların uygun materyallerle düzenli olarak temizlenmesi gereklidir.

Üretici firmalar, temizleme ve dezenfeksiyon için görüntü plağı temizleme mendillerinin kullanımasını önermektedir. ${ }^{55} \mathrm{Bu}$ tek kullanımlık mendiller, $4 \mathrm{~g}$ izopropil alkol içerir ve yeterli etkinlik için 15 ila 30 sn uygulama süresi önerilmektedir. Görüntü plakları da temizlendikten sonra kurutulmalıdır. Plakaların silinmesi aynı zamanda plak kalitesi üzerinde olumsuz bir etkiye sahip olabilir. Bu nedenle Kalathingal ve ark. ${ }^{28}$ çiziklerin önlenmesi için, her adımda eldiven ile plakların kullanımını, sadece plak yüzeyinde görünür bir kir olduğunda hafifçe silinmesini, yüzeydeki toz parçacıklarını, vücut yağı kirlenmesini ve lekeleri çıkarmak için \%95 alkollü yumuşak bir bezle temizlenmesi önermiştir.

Dezenfektanların plaklarda hasara neden olabileceği de unutulmamalıdır. ${ }^{18}$

\section{3- Tarayıcı ile İlişkili Artifaktlar}

Çalışkan ve Sumen'in çalışmasında, tarayıcıya bağlı artifaktlar arasında en çok düz çizgi (\%42,2, n = 887/2100) ve zikzaklı çizgi $(\% 8,84, n=184 / 2100)$ şeklindeki artifaktlar izlenmiştir. ${ }^{29}$ Deniz ve Kaya, ${ }^{31}$ tarayıcılar ile ilgili hataların oldukça az olduğunu belirtmiş ve en yaygın tarayıcı hatasını dar tarama penceresindeki kir ve toz birikiminin neden olduğu horizontal beyaz çizgiler olarak tespit etmiştir. Benzer şekilde Chiu ve ark..$^{13}$ tarayıcıya bağlı artifaktların oluşma sıkığının yüksek olmadığını; ancak bu tip artifaktların tanınması gerektiğini bildirmişlerdir.

\section{a) Silindir artifaktları}

Tarayıcıda, latent imajın lazerle taranması ve daha sonra yüksek yoğunluklu halojen lamba ile silinmesi için görüntüleme plağının taşınmasında silindirler kullanılır. FP, bu işlem sırasında silindirlerle sürekli temas halindedir. ${ }^{38}$

Uyumsuzluk artifaktı, dijitalleştiricideki silindirlerin bozulması nedeniyle, görüntü kontrastında değişime neden olan hatalı tarama gerçekleşir. Silindirlerin periyodik temizliği ile bu artifakt önlenebilir. ${ }^{38}$

Görüntüleme plağı silindirlerden taşınırken mekanik olarak zarar görebilir. Görüntülerde, nokta şeklinde görülen fokal radyoopasiteler izlenir. Bu durumda silindirlerin hızlı bir şekilde temizlenmesi gerekir. ${ }^{38}$

Silindirlerdeki kir, hızlı tarama yönünde uzanan horizontal gri çizgiler (çeşitli radyoopasitelerde) şeklinde artifakta neden olur. Çözüm; taşıma mekanizmasının temizlenmesi, gerekirse taşıyıcı bantların değiştirilmesidir. ${ }^{31}$

Silindirlerin taşıma düzeneğinden kayması sonucu oluşan artifaktlar, yarım okunmuş görüntü şeklinde görüntülenir. Yükleme silindirlerinin periyodik temizliği ve kalibrasyonu gereklidir. $^{38}$

\section{b) Plak Okuyucu Artifaktları}

Tarama sırasında tarayıcının dar tarama penceresindeki sabit kalan kir ve toz parçacıkları, radyografide yavaş tarama yönüne paralel olan radyoopak düz çizgi oluşmasına neden olurken hafifçe hareket eden kir ve toz parçacıkları ise radyografide yavaş tarama yönüne paralel olan radyoopak zikzaklı bir çizgiye neden olur. Ayrıca, her hızlı tarama döngüsünden elde edilen görünür ışık, parabolik aynalar veya ışık toplayıcı üzerindeki toz ve kir nedeniyle foto-çoğaltıcı tüpe ulaşamayabilir. Blokaja neden olan toz parçacıkları ve kir temizlenmedikçe veya kendiliğinden hareket etmedikçe, aynı görüntüyü tam olarak aynı yerde izlenir (Resim 5a).

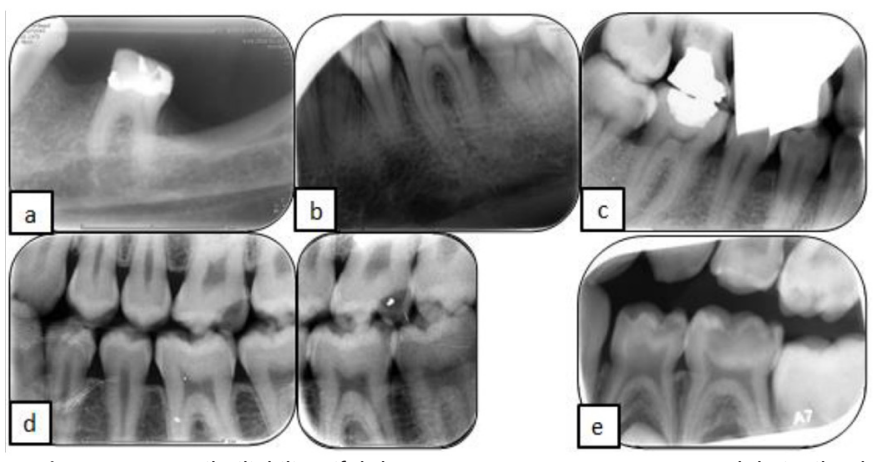

Resim 5. Tarayıcı ile ilişkili artifaktlar. a. Yavaş tarama yönüne paralel çizgiler, b Cizgilenme, c. Atlanmış görüntü parçası, d. Plaka boyutu belirleme hatası. e. Plağın tarayıcıya eğimli yerleştirilmesi.

Üretici firmalar, kirlenme durumunda tarayıcının taşıma mekanizması ve lazer açıklığının temizlenmesini önermektedir. Dental ünitelerinin hava spreyi, tarayıcının parçalarını çıkarmadan temizlik için kullanılabileceği belirtilmiştir. ${ }^{23}$ Ancak hava spreyi, dar tarama penceresinden pisliği cihazın daha derinine itebilir. Ek olarak, cihazı temizlemek için sprey temizleyiciler kullanıldığında ünite içine sıvı girebilir. ${ }^{53}$

\section{c) Düz Radyolüsent Çizgiler}

Literatürde radyolüsent artifaktlar hakkında tam bir fikir birliği sağlanamamıştır. Shetty ve ark., ${ }^{38}$ görselleştirilmeyen alanların ve eksik satır veya piksellerin ani elektrik kesintilerinden kaynaklanabileceğini bildirmiştir. Deniz ve Kaya, ${ }^{31}$ bir fantom çeneden aldıkları ardışık 4 görüntüde farklı özelliklere sahip radyolüsent bantlar gözlendiğini, bu bantların hızı tarama yönüne paralel çoklu radyolüsent çizgiler gibi göründüğünü ve cihaz bağlantıları tekrar yerine yerleştirildikten sonra hatanın azaldığını belirtmiştir. Üreticiler elektromanyetik girişim artifaktlarının yakın çevredeki, elektronik ekipmanı etkileyebilecek, elektrik hatlarının varlığından kaynaklandığını bildirmektedir. Bu nedenle, uygun elektromanyetik korumalık eklenmesi önerilmektedir. Mevcut voltaj kalitesinin tipik bir ofis veya hastane ortamına uygun olması gerekmektedir. Cihaz ayrıca kesintisiz bir güç kaynağından veya bataryadan da beslenmelidir. ${ }^{53}$ 
Çalışkan ve Sumer, ${ }^{29}$ bu görüntüleri çizgilenme artifaktı olarak nitelendirmiştir. Görüntüde hızlı tarama yönüne paralel olarak görülen, artan bir mesafeye sahip birden çok radyolusent çizgilerin; uyarıcı lazerin ışık yoğunluğunda anlık değişiklikler, hızıı tarama döngüleri ve görüntü plağı geçişi arasındaki senkronizasyon kaybından kaynaklandığını ileri sürülmüştür. (Resim 5b).

Bu tip artifaktlarla ilgili daha fazla araştırmaya intiyaç vardir.

\section{d) Atlanmış Görüntü Parçası}

Lazer ışınının hızı tarama yönünde stimülasyonu ile plakların yavaş tarama yönünde silindirler ve bir taşıyıcı bantla ilerlemesi arasındaki senkronizasyon bozulursa hızı tarama yönüne paralel atlanmış görüntü parçaları oluşmaktadır (Resim 5c).

\section{e) Taşıyıcı Bant Yüzey Soyulması}

Taşıyıcı bant yüzeyinin soyulması ve soyulmuş kısmın plak ile dar tarama penceresi arasında yerleşmesi görüntünün bir köşesinde genellikle farklı şekillerde görülen düzensiz fakat iyi sınırlı bir görünüm oluşmasına neden olur.

\section{f) Silme Hatası}

Taranan plakaların bir sonraki radyografik görüntüleme işleminde kullanılması için residuel imaj oluşturabilecek tüm sinyaller ortadan kaldırılmalıdır. Birçok tarayıcı, tarama işleminin hemen ardından otomatik olarak plaklara yüksek yoğunlukta ışık uygulayarak kalan sinyalleri silebilme ayarına sahiptir. Nadiren, tarayıcının silme işlemini yapmadığı veya yetersiz yaptığı plakların tekrar kullanımı çift ışınlama sonucu oluşan radyografik görüntülerle aynı özelliğe sahiptir. Çözüm, ayarları kontrol etmektir. Silme ayarı en yüksek silme gücünde, tarama hızı en düşük ayarda olmalıdır. Tarayıcıların bu silme işlevi; zaman kazanma, görüntüleme işlemini basitleştirme ve ayrı bir silici gereksinimini ortadan kaldırma gibi avantajlara sahiptir. Bununla birlikte tarayıcı artifaktları, görüntüyü tekrarlamak zorunda kalmadan FP yeniden okunarak (başka bir tarayıcı ile) düzeltilebilir. Bunun için silme işlevi özelliği kaldırılırsa görüntüyü yeniden taramak için ikinci bir şans olur ve görüntülemenin tekrarlanması gerekmez. ${ }^{13}$

\section{g) Lazer Ünitesine Bağlı Hatalar}

Lazer ünitesi çok çeşitli hatalara katkıda bulunabilir. Deniz ve Kaya, ${ }^{31}$ lazer ünitesine bağlı hataları; lazer ünitesinin kirliliği ve lazer ünitesi arızaları olarak gruplandırmıştır.

Lazer ünitesinin kirliliği; lazer açıklığında toz parçacıkları ve kir birikmesi sonucu radyoopak bir çizgi ile 2'ye ayrılmış görüntü izlenir. Lazer açıklığının temizlenmesi gerekir. ${ }^{31}$

Lazer ünitesi arızası; parçalanmış görüntüler, kumlu görünüm, dişli benzeri görüntü, görüntünün bölünmesi şeklinde görülebilir. Üretici firmalar bu sorunu çözmek için lazer ünitesini değiştirilmesini tavsiye etmektedir. ${ }^{52,53}$

\section{h) Plak Boyutu Belirleme Hataları}

Bu gruptaki hatalar az rastlanan artifaktlardır. ${ }^{29}$
Birleştirme; intraoral boyuttaki plakların çoklu taramasında, tarayıcının yanlışıkla panoramik veya sefalometrik boyutta plak tarama belirlemesi ile oluşur. Aynı tarama prosedüründeki farklı plaklardan görüntülerin toplanmasıyla büyük bir görüntü oluşur, plaklar arasındaki alan beyaz olarak görülür.

İkiye bölme; daha küçük plak boyutu belirleme, bozuk güç kaynağı veya yazılımla ilgili diğer arızalar sonucu bir plak taramasından birbirinin devamı olan iki ayrı görüntü olarak izlenmesidir.

Tamamlanmamış tarama; tarayıcı geniş cone-cut alanına ulaştığında tarama prosedürünü durdurması nedeniyle oluşur. Plak ile karşılaştıııldığında daha küçük radyografik görüntü boyutu elde edilir (Resim 5d).

\section{4- Yazılım Hataları}

Hatalı işlem menüsü ayarları; yanlış histogram normalizasyonuna, hatalı dinamik aralık ölçeklendirmesine ve uygun olmayan filmi densitesi üretimine neden olabilir. ${ }^{40}$ Ancak geriye dönük incelemelerde bu hatalı ayarların gerçek nedenlerinin belirlenmesi zordur. Diğer yazılım artifaktları, hatalı kenar maskeleme, ikiye bölme, bağlantı hatası artifaktları ve veri kablosu arızalarıdır. ${ }^{52,53,56}$

Kenar maskeleme, klinik görüntülerin kalitesini artırmak için tasarlanmıştır. Kusurlu kenar maskeleme, görüntünün bir bölümünün kaybolmasına neden olur, bu cone-cut veya metal artifaktına benzer. ${ }^{52,53}$ Ayrıca yetersiz kenar maskeleme, görüntünün bulanıklaşmasına neden olur. ${ }^{56}$ Ancak hatalı kenar maskeleme artifaktını cone-cut'dan güvenli bir şekilde ayırt etmek zordur. Çözüm; yazılım programını güncellemek, eğer yazılım programı güncellenemiyorsa, kenar maskeleme aracının kapatılmasıdır.

Bağlantı hatası artifaktları: Dijitalleştirme işleminden sonra görüntü elektronik olarak görüntüleme bilgisayarına aktarılır. Bu görüntü aktarımı sırasında bir elektrik kesintisi olursa, ortaya çıkan görüntü bozulabilir ve daha fazla düzenlenemez. Bu artifakt kayıp pikseller olarak görülür. ${ }^{56}$ Veri kabloları kontrol sinyallerini; lazer cihazı, ışın deflektörü ve foto-çoğaltıcı tüp gibi okuyunun çeşitli modüllerine götürür ve ayrıca lazer cihazına ve foto-çoğaltıcı tüplere güç sağlamadan sorumludur. Bu kablolar üzerinden farkIı modüllere iletimdeki bozukluk artifakta neden olabilir. Çözüm, veri kablolarını yeniden kontrol etmek ve değiştirmektir. ${ }^{38}$

\section{5- Operatör ile İlişkili Hatalar}

FP'lerin tarayıcıya eğimli yerleştirilmesi görüntüde artifakta neden olmaktadır (Şekil 5e). Bu artifakt, Gulsahi ve Secgin'in yaptıkları çalışmada en sık pediatrik yaş grubunda görülmüştür. Araştırmacılar bu hatanın sebebini FP'lerin tek kullanımlık paket içerisindeki hareketi olarak belirtmiştir. ${ }^{30}$ Klinik gözlemlerimiz bu tip artifaktın pedodonti hastalarında sıklıkla görüldüğü yönündedir; ancak bu durumun pediatrik hastalarda kullanılan 0 ya da 1 boyutundaki FP'lerin tarayıcıya hatalı yerleştirilmesinden kaynaklandı- 
ğı düşünülmektedir.

\section{SONUÇ}

Günümüzde FP sistemi oldukça yaygın kullanıma sahiptir. Bu sistemin etkin kullanımı için özelliklerinin ve hatalarının iyi anlaşılması gerekmektedir. Her ne kadar FP sistemleri, konvansiyonel sistemlerinin eksikliklerinin üstesinden gelmek için farklı bileşenler kullanıyor olsa da, bu bileşenler yeni artifaktları beraberinde getirmektedir. Artifaktların ve nedenlerinin hekimler tarafından bilinmesi gereklidir. Böylece, ışınlama işlemlerinin tekrar edilmesi azaltılabilir ve hasta, hekim, radyoloji personeli ile çevrenin gereksiz radyasyona maruziyeti en az düzeye indirilebilir. Artifaktların çözümlerinin belirlenmesi ile tiplerinin tanımlanması; başarılı bir radyografik görüntüleme, tanısal hataların engellenmesi ve buna bağlı malpraktislerin önlenmesi açısından önemlidir.

\section{TEŞEKKÜR}

Makaledeki bütün görüntüler fakültemizin Ağız, Diş ve Çene Radyolojisi ABD arşivinden alınmıştır.

Bütün görüntüler; Gendex GXPS-500 (Kavo, Biberach, Germany) tarayıcı ve DenOptix ${ }^{\circledR}$ (Gendex ${ }^{\circledR}$ DenOptix ${ }^{\circledR}$ Imaging system) marka plak kullanılarak elde edilmiştir. Sadece Resim 5e'deki görüntüde farklı olarak Digora Optime (Soredex, Tuusula, Finland) marka FP sistemi kullanılmıştır.

\section{KAYNAKLAR}

1. White SC, Pharoah MJ. Oral Radiology Principles and Interpretation. 5 ed. St. Louis (MO); Mosby: 2004. p. 225 44.

2. Soğur $E$, Baskı BG. İntraoral görüntüleme sistemleri. Atatürk Üniv Diş Hek Fak Derg 2011; 21: 249-254.

3. Van der Stelt PF. Filmless imaging: the uses of digital radiography in dental practice. J Am Dent Assoc 2005; 136: 1379-1387.

4. Berkhout WER, Verheij JGC, Syriopoulos K, Li G, Sanderink GCH, Van Der Stelt PF. Detection of proximal caries with high-resolution and standard resolution digital radiographic systems. Dentomaxillofac Radiol 2007; 36: 204-210.

5. Richards AG, Colquitt WN. Reduction in dental x-ray exposures during the past 60 years. J Am Dent Assoc 1981; 103: 713-718.

6. Farman AG, Farman TT. A comparison of 18 different $x$-ray detectors currently used in dentistry. Oral Surg Oral Med Oral Pathol Oral Radiol Endod 2005; 99: 485-489.

7. Vandenberghe $B$, Jacobs R, Bosmans $H$. Modern dental imaging: a review of the current technology and clinical applications in dental practice. Eur Radiol. 2010; 20: 2637-2655.

8. Wakoh M, Kuroyanagi K. Digital imaging modalities for dental practice. Bull Tokyo Dent Coll 2001; 42: 1-14.

9. Malleshi SN, Mahima VG, Raina A, Patil K. A subjective assessment of perceived clarity of indirect digital ima- ges and processed digital images with conventional intra-oral periapical radiographs. J Clin Diagn Res 2013; 7: 1793-1796.

10. Wenzel A, Møystad A. Work flow with digital intraoral radiography: A systematic review. Acta Odontol Scand 2010; 68: 106-114.

11. Van der Stelt PF. Better imaging: The advantages of digital radiography. J Am Dent Assoc 2008; 139 Suppl: 7S-13.

12. Berkhut WE, Sanderink GC, Van der Stelt PF. A comparison of digital and film radiography in Dutch dental practices assessed by questionnaire. Dentomaxillofac Radiol 2002; 31: 93-99.

13. Chiu HL, Lin $\mathrm{SH}$, Chen $\mathrm{CH}$, Wang WC, Chen JY, Chen YK, et al. Analysis of photostimulable phosphor plate image artifacts in an oral and maxillofacial radiology department. Oral Surg Oral Med Oral Pathol Oral Radiol Endod 2008; 106: 749-756.

14. Borg E. Some characteristics of solid-state and photo-stimulable phosphor detectors for intra-oral radiography. Swed Dent J 1999; 139(Suppl): 1-67.

15. Hildebolt CF, Couture RA, Whiting BR. Dental photostimulable phosphor radiography. Dent Clin North Am 2000; 44: 273-297.

16. Wenzel A, Frandsen $E$, Hintze H. Patient discomfort and crossinfection control in bite-wing examinations with a storage phosphor plate and a CCD-based sensor. J Dent 1999; 27: 243-246.

17. Roberts MW, Mol A. Clinical techniques to reduce sensor plate damage in PSP digital radiography. J Dent Child (Chic) 2004; 71: 169-170.

18. Akçiçek G, Çağırankaya LB, Avcu N. Fosfor Plak Sistemlerinde Karşılaşılan Temel Sorunlar. Atatürk Üniversitesi Diş Hekimliği Fakültesi Dergisi, 2016.

19. Wenzel A. A review of dentists' use of digital radiog raphy and caries diagnosis with digital systems. Dentomaxillofac Radiol 2006; 35: 307-314.

20. Brennan J. An introduction to digital radiography in dentistry. J Orthod 2002; 29: 66-69.

21. Stamatakis HC, Welander U, McDavid WD. Physical properties of a photostimulable phosphor system for intra-oral radiography. Dentomaxillofac Radiol 2000; 29: 28-34.

22. Borg E, Attaelmanan A, Gröndahl HG. Image plate systems differ in physical performance. Oral Surg Oral Med Oral Pathol Oral Radiol Endod 2000; 89: 118-124.

23. Petrikowski CG. Introducing digital radiography in the dental office: An overview. J Can Dent Assoc 2005; 71: 651.

24. Ramamurthy $R$, Canning CF, Scheetz JP, Farman AG. Impact of ambient lighting intensity and duration on the signal-to-noise ratio of images from photostimulable phosphor plates processed using DenOptix and ScanX 
systems. Dentomaxillofac Radiol 2004; 33: 307-311.

25. Akdeniz BG, Gröndahl HG, Kose T. Effect of delayed scanning of storage phosphor plates. Oral Surg Oral Med Oral Pathol Oral Radiol Endod 2005; 99: 603-607.

26. Martins MG, Neto FH, Whaites EJ. Analysis of digital images acquired using different phosphor storage plates (PSPs) subjected to varying reading times and storage conditions. Dentomaxillofac Radiol 2003; 32: 186-190.

27. Ang DB, Angelopoulos C, Katz JO. How does signal fade on photo-stimulable storage phosphor imaging plates when scanned with a delay and what is the effect on image quality? Oral Surg Oral Med Oral Pathol Oral Radiol Endod 2006; 102: 673-679.

28. Kalathingal SM, Shrout MK, Comer C, Brady C. Rating the extent of surface scratches on photostimulable storage phosphor plates in a dental school environment. Dentomaxillofac Radiol 2010; 39: 179-183.

29. Çalışkan A, Sumer, AP. Definition, classification and retrospective analysis of photostimulable phosphor image artefacts and errors in intraoral dental radiography. Dentomaxillofac Radiol 2017; 46: 20160188.

30. Gulsahi A, Secgin CK. Assessment of intraoral image artifacts related to photostimulable phosphor plates in a dentomaxillofacial radiology department. Niger $\mathrm{J}$ Clin Pract 2016; 19: 248-53.

31. Deniz Y, Kaya S. Determination and classification of intraoral phosphor storage plate artifacts and errors. Imaging science in dentistry, 2019; 49: 219-228.

32. Hubar J.S, Caballero P. Fundamentals of Oral and Maxillofacial Radiology. Wiley; 2017.

33. Ghom AG. Textbook of Oral Radiology-E-Book. Elsevier Health Sciences; 2017.

34. White SC, Pharoah MJ. Oral Radiology Principles and Interpretation. 7th ed. St. Louis: Mosby; 2014; p. 46,94.

35. Langlais R. Exercises in Oral Radiology and Interpretation 4th Edition, Saunders; 2004.

36. Dixon J, Biggi M, Weller R. Common artefacts and pitfalls in equine computed and digital radiography and how to avoid them. Equine Veterinary Education; 2016.

37. Nuth EK, Armbrust LJ, Roush JK, Biller DS. Identification and effects of common errors and artifacts on the perceived quality of radiographs. J. Am. Vet. Med. Assoc. 2014; 244:961-967.

38. Shetty CM, Barthur A, Kambadakone A, Narayanan $\mathrm{N}, \mathrm{Kv}$ R. Computed radiography image artifacts revisited. American Journal of Roentgenology 2011; 196: W37-W47. 39. Harorlı A, Akgül HM, Dağıstan S. Dişhekimliği Radyolojisi. 1.baskı. Erzurum: Eser Ofset Matbaacılık; 2006.

40. Seibert JA, Bogucki TM, Ciona T, Huda W, Karellas A, Mercier JR, et al. Acceptance testing and quality control of photostimulable storage phosphor imaging systems. Report of AAPM task group 10. College Park, MD: American Association of Physicists in Medicine; 2006.
41. Denoptix ${ }^{\circledast}$ Digital Imaging System - User Manual and Installation Guide, Dentsply Gendex, Des Plaines, IL, USA. 42. $A / T$ Scan $X^{\text {Tm }}$ Digital Imaging System Operator's Manual Air Techniques Inc.P-9. www.airtechniques.com.

43. Dürr digital diagnostic radiography. The time is right for a change in diagnostic radiography [Product brochure on the internet]. Bietigheim-Bissingen: Dürr Dental GmbH \& Co. KG.

44. Ludlow JB, Mol A. Digital imaging. In: White SC, Pharoah $\mathrm{MJ}$, eds. Oral radiology: principles and interpretation. 7th edn. St Louis, MO: Mosby; 2014. pp. 41-62.

45. Farman AG, Farman TT, Molteni R. Effects of visible light on storage phosphors used in dentistry. In: Lemke $\mathrm{HU}$, et al (eds). Computer assisted radiology and surgery. Amsterdam: Elsevier Science, 1999; p. 1085.

46. Molteni R. Effect of visible light on photostimulated-phosphor imaging plates. International Congress Series 2003; 1256: 1199-205.

47. Eskandarloo A, Yousefi A, Soheili S, Ghazikhanloo $K$, Amini $\mathrm{P}$, Mohammadpoor $\mathrm{H}$. Evaluation of the Effect of Light and Scanning Time Delay on The Image Quality of Intra Oral Photostimulable Phosphor Plates. The open dentistry journal, 2017; 11: 690.

48. Ergun $S$, Guneri $P$, Ilguy $D$, Ilguy $M$, Boyacıoğlu $H$. How many times can we use a phosphor plate? A priminary study. Dentomaxillofac Radiol 2009; 38: 42-47.

49. Bedard A, Davis TD, Angelopoulos C. Storage phosphor plates: how durable are they as a digital dental radiographic system? J Contemp Dent Pract 2004; 5: 57 69.

50. Buchanan A, Benton B, Carraway A, Looney S, Kalathingal $S$. Perception versus reality-findings from a phosphor plate quality assurance study. Oral surgery, oral medicine, oral pathology and oral radiology, 2017; 123: 496-501.

51. Kavo.com [Internet]. Biberach: SOREDEXTM DIGORATM Optime; c2019 [cited 2019 Jan 7]. Available from: https:// www.kavo.com/dental-x-ray-machines-and-diagnostics/ scan-exam-intraoral\#docs.

52. Duerrdental.com [Internet]. Bietigheim-Bissingen: VistaScan Mini Easy. Available from: https://www.duerrdental.com/ en/products/imaging/vistascan-image-plate-scanner/vistascan- mini-easy/.

53. Webber RL, Ruttimann UE, Groenhuis RA. Computer correction of projective distortions in dental radiographs. J Dent Res 1984; 63: 1032-1036.

54. Product information VistaScan image plate cleaning wipe [Product brochure on the internet]. Bietigheim-Bissingen: Dürr Dental AG.

55. Seeram E. Computed radiography: physics and technology. In: Digital radiography. Singapore: Springer; 2019; p. 41-63.

56. Willis C, Thompson SK, Shepard J. Artifacts and misadventures in digital radiography. Appl Radiol 2004; January 1: 11-20. 